\title{
Do Physicians Clean Their Hands? Insights From a Covert Observational Study
}

\author{
Adam Kovacs-Litman, BSc ${ }^{1 *}$, Kimberly Wong, BSc ${ }^{1}$, Kaveh G. Shojania, MD ${ }^{1,2}$, Sandra Callery, RN, MHSc, ClC ${ }^{3}$, \\ Mary Vearncombe, $\mathrm{MD}^{3}$, Jerome A. Leis, MD, MSc $\mathrm{M}^{1,2,4 *}$
}

\begin{abstract}
${ }^{1}$ Centre for Quality Improvement and Patient Safety, University of Toronto, Toronto, Ontario, Canada; ${ }^{2}$ Department of Medicine, University of Toronto, Toronto, Ontario, Canada; ' ${ }^{3}$ Department of Microbiology, Sunnybrook Health Sciences Centre, Toronto, Ontario, Canada; ${ }^{4}$ Divsion of Infectious Diseases, Sunnybrook Health Sciences Centre, Toronto, Ontario, Canada.
\end{abstract}

Physicians are notorious for poor hand hygiene $(\mathrm{HH})$ compliance. We wondered if lower performance by physicians compared with other health professionals might reflect differences in the Hawthorne effect. We introduced covert $\mathrm{HH}$ observers to see if performance differences between physicians and nurses decreased and to gain further insights into physician $\mathrm{HH}$ behaviors. Following training and validation with a hospital $\mathrm{HH}$ auditor, 2 students covertly measured $\mathrm{HH}$ during clinical rotations. Students rotated off clinical services every week to increase exposure to different providers and minimize risk of exposing the covert observation. We compared covertly measured $\mathrm{HH}$ compliance with data from overt observation by hospital auditors during the same time period. Covert observation produced much lower $\mathrm{HH}$ compliance than recorded by hospital auditors during the same time period: $50.0 \% \quad(799 / 1597)$ versus
83.7\% (2769/3309) $(P<0.0002)$. The difference in physician compliance between hospital auditors and covert observers was $19.0 \%$ (73.2\% vs $54.2 \%)$; for nurses this difference was much higher at $40.7 \%(85.8 \%$ vs $45.1 \%)(P<0.0001)$. Physician trainees showed markedly better compliance when attending staff cleaned their hands compared with encounters when attending did not $(79.5 \%$ vs $18.9 \%$; $P<$ 0.0002). Our study suggests that traditional $\mathrm{HH}$ audits not only overstate $\mathrm{HH}$ performance overall, but can lead to inaccurate inferences about performance by professional groupings due to relative differences in the Hawthorne effect. We suggest that future improvement efforts will rely on more accurate $\mathrm{HH}$ monitoring systems and strong attending physician leadership to set an example for trainees. Journal of Hospital Medicine 2016;11:862-864. (C) 2016 Society of Hospital Medicine
Hand hygiene $(\mathrm{HH})$ is believed to be one of the single most important interventions to prevent healthcareassociated infection, yet physicians are notorious for their poor compliance. ${ }^{1-3}$ At our 800 -bed acute care academic hospital, we implemented a multifaceted $\mathrm{HH}$ program ${ }^{4}$ in 2007 , which was associated with improved $\mathrm{HH}$ compliance rates from $43 \%$ to $87 \%$. Despite this improvement, $\mathrm{HH}$ compliance among physicians remained suboptimal, with rates below $60 \%$ in some patient areas. A targeted campaign focused on recruitment of physician champions, resulted in some improvement, but physician compliance has consistently remained below performance of nurses $(70 \%-75 \%$ for physicians vs $85 \%-90 \%$ for nurses).

Our experience parallels the results seen in multinational surveys demonstrating consistently lower physician $\mathrm{HH}$ compliance. ${ }^{5}$ Given the multiple improvement

\footnotetext{
*Address for correspondence and reprint requests: Jerome A. Leis, MD, Sunnybrook Health Sciences Centre, H463, 2075 Bayview Avenue, Toronto, Ontario, M4N 3M5 Canada; Telephone: 416-480-6100 x89352; Fax: 416-480-6769; E-mail: jerome.leis@sunnybrook.ca

Additional Supporting Information may be found in the online version of this article.

Received: April 8, 2016; Revised: May 29, 2016; Accepted: May 31 2016

2016 Society of Hospital Medicine DOI 10.1002/jhm.2632

Published online in Wiley Online Library (Wileyonlinelibrary.com).
}

efforts directed at physicians and the apparent ceiling observed in $\mathrm{HH}$ performance, we wanted to confirm whether physicians are truly recalcitrant to cleaning their hands, or whether lower compliance among physicians reflected a differential in the Hawthorne effect inherent to direct observation methods. Specifically, we wondered if nurses tend to recognize auditors more readily than physicians and therefore show higher apparent $\mathrm{HH}$ compliance when auditors are present. We also wanted to verify whether the behavior of attending physicians influenced compliance of their physician trainees. To test these hypotheses, we trained 2 clinical observers to covertly measure $\mathrm{HH}$ compliance of nurses and physicians on 3 different clinical services.

\section{METHODS}

Between May 27, 2015 and July 31, 2015, 2 student observers joined clinical rotations on physician and nursing teams, respectively. Healthcare teams were unaware that the student observers were measuring $\mathrm{HH}$ compliance during their clinical rotation. Students rotated in the emergency department, general medical and surgical wards for no more than 1 week at a time to increase exposure to different providers and minimize risk of exposing the covert observation.

Prior to the study period, the students underwent training and validation with a hospital $\mathrm{HH}$ auditor at another clinical setting offsite to avoid any recognition 


\begin{tabular}{|c|c|c|c|}
\hline & $\begin{array}{l}\text { Covert Observers, } \\
\text { Compliance } \\
(95 \% \mathrm{Cl})\end{array}$ & $\begin{array}{l}\text { Hospital Auditors, } \\
\text { Compliance } \\
(95 \% \mathrm{Cl})\end{array}$ & Difference \\
\hline $\begin{array}{l}\text { Overall hand hygiene } \\
\text { compliance }\end{array}$ & $50.0 \%(47.6-52.5)$ & $83.7 \%(82.4-84.9)$ & $33.7 \%$ \\
\hline \multicolumn{4}{|l|}{ Service } \\
\hline Medicine & $58.9 \%(55.3-62.5)$ & $85.0 \%(82.7-87.3)$ & $26.1 \%$ \\
\hline Surgery & $45.7 \%(41.6-49.8)$ & $91.0 \%(87.5-93.7)$ & $45.3 \%$ \\
\hline Emergency & $43.9 \%(38.9-49.9)$ & $73.8 \%$ (68.9-78.2) & $29.9 \%$ \\
\hline Nurses & $45.1 \%(41.5-48.7)$ & $85.8 \%(83.3-87.9)$ & $40.7 \%$ \\
\hline \multicolumn{4}{|l|}{ Physicians } \\
\hline Overall compliance & $54.2 \%(50.9-57.1)$ & $73.2 \%(67.3-78.4)$ & $19.0 \%$ \\
\hline Trainee compliance* & $79.5 \%(73.6-84.3)$ & & \\
\hline Trainee compliance $\dagger$ & $18.9 \%(13.3-26.1)$ & & \\
\hline
\end{tabular}

NOTE: Abbreviations: $\mathrm{Cl}$, confidence interval. *When attending physicians cleaned their hands. †When attending physicians did not clean their hands.

of these students by healthcare providers as observers of $\mathrm{HH}$ at the main hospital. Training with the auditors occurred until interobserver agreement between all $\mathrm{HH}$ opportunities reached $100 \%$ agreement for 2 consecutive observation days.

During their rotations, students covertly recorded $\mathrm{HH}$ compliance based on moments of hand hygiene ${ }^{4}$ and also noted location, presence, and compliance of the attending physician, team size during patient encounter, and isolation requirements. Both students measured $\mathrm{HH}$ compliance of nurses and physicians around them. Although students spent the majority of their time with their assigned physician or nurse teams, they did not limit their observations to these individuals only, but recorded compliance of any nurse or physician on the ward as long as they were within sight during an $\mathrm{HH}$ opportunity. To limit clustering of observations of the same healthcare worker, up to a maximum of 2 observations per healthcare worker per day was recorded.

We compared covertly measured $\mathrm{HH}$ compliance with data from overt observation by hospital auditors during the same time period. Differences in proportion of $\mathrm{HH}$ compliance were compared with hospital audits during the same period with a $\chi^{2}$ test. Difference between differences in overtly and covertly measured $\mathrm{HH}$ compliance for nurses and physicians was compared using Breslow day test.

The study was approved by the hospital's research ethics board. Although deception was used in this study, ${ }^{2,6}$ all data were collected for quality improvement purposes, and the aggregate results were disclosed to hospital staff following the study.

\section{RESULTS}

Covertly observed $\mathrm{HH}$ compliance was 50.0\% (799/ 1597) compared with $83.7 \%$ (2769/3309) recorded by hospital auditors during the same time period $(P<0.0002)$ (Table 1$)$. There was no significant difference in the compliance measured by each student $(50.1 \%, 473 / 928$ vs $48.7 \%, 326 / 669)(P=0.3)$, and their results were combined for the rest of the analysis. Compliance before contact with the patient or patient environment was $43.1 \%$ (344/798), $74.3 \%$ (26/35) before clean/aseptic procedures, 34.8\% (8/23) after potential body fluid exposure, and $56.8 \%$ (483/ 851 ) after contact with the patient or patient environment. Healthcare providers examining patients with isolation precautions were found to have a $\mathrm{HH}$ compliance of $74.8 \%$ (101/135) compared to $47.0 \%$ (385/ $820)$ when isolation precautions were not required $(P$ $<0.0002)$.

Hospital auditor data showed that surgery and medicine had similarly high rates of compliance $(91.0 \%$ and $85.0 \%$, respectively), whereas the emergency department had a notably lower rate of $73.8 \%$. Covert observation confirmed a lower rate in the emergency department $(43.9 \%)$, but showed a higher compliance on general medicine than on surgery $(58.9 \%$ vs $45.7 \% ; P=0.02)$. The difference in physician compliance between hospital auditors and covert observers was $19.0 \%$ (73.2\%, $175 / 239$ vs. $54.2 \%$, 469/865); for nurses this difference was much higher at $40.7 \% \quad(85.8 \%, 754 / 879$ vs. $45.1 \%$, 330/732) $(P<0.0001)$ (Table 1).

In terms of physician compliance, primary teams tended to have lower HH compliance of $50.4 \%$ (323/ 641) compared with consulting services at $57.0 \%$ $(158 / 277)(P=0.06)$. Team rounds of $\geq 3$ members were associated with higher compliance compared with encounters involving $<3$ members $(62.1 \%, 282 /$ 454 vs. $42.0 \%, 128 / 308)(P<0.0002)$. Presence of attending physician did not affect trainee $\mathrm{HH}$ compliance $(55.5 \%, 201 / 362$ when attending present vs. $56.8 \%, 133 / 234$ when attending absent; $P=0.79$ ). However, trainee HH compliance improved markedly when attending staff cleaned their hands and decreased markedly when they did not $(79.5 \%, 174 /$ 219 vs. $18.9 \%, 27 / 143 ; P<0.0002)$.

\section{DISCUSSION}

We introduced covert $\mathrm{HH}$ observers at our hospital to determine whether differences in Hawthorne effect accounted for measured disparity between physician $\mathrm{HH}$ compliance, and to gain further insights into the barriers and enablers of physician $\mathrm{HH}$ compliance. We discovered that performance differences between physicians and nurses decreased when neither group was aware that $\mathrm{HH}$ was being measured, suggesting that healthcare professions are differentially affected by the Hawthorne effect. This difference may be explained by the continuity of nurses on the ward that makes them more aware of visitors like HH auditors, ${ }^{7}$ compared with physicians who rotate periodically on the ward. 
Although hospital auditors play a central role in $\mathrm{HH}$ education through in-the-moment feedback, use of these data to benchmark performance can lead to inappropriate inferences about $\mathrm{HH}$ compliance. Prior studies using automated $\mathrm{HH}$ surveillance have suggested that the magnitude of the Hawthorne effect varies based on baseline $\mathrm{HH}$ rates, ${ }^{8}$ whereas our study suggests a differential Hawthorne effect between professions and clinical services. If we relied only on auditor data, we would have continued to believe that only physicians in our organization had poor $\mathrm{HH}$ compliance, and we would not be aware of the global nature of the $\mathrm{HH}$ problem.

Our results are similar to that of Pan et al., who used covert medical students to measure $\mathrm{HH}$ and found compliance of $44.1 \%$ compared with $94.1 \%$ by unit auditors. ${ }^{2}$ Because their study involved an active feedback intervention, the differential in Hawthorne effect between professions could not be reliably assessed. However, they observed a progressive increase in nurse $\mathrm{HH}$ compliance using covert observation methods, suggesting improvement in $\mathrm{HH}$ performance independent of observer bias. ${ }^{7}$

Covert observation in our study also provided important insights regarding barriers and enablers of $\mathrm{HH}$ compliance. Self-preservation behaviors were common among both nurses and physicians, as $\mathrm{HH}$ compliance was consistently higher after patient contact compared to before or when seeing patients who required additional precautions. This finding confirms that the perceived risk of transmission seems to be a powerful motivating factor for $\mathrm{HH} .{ }^{9}$ Larger groups of trainees were more likely to clean their hands, likely due to peer effects. ${ }^{10}$ The strong impact of role modeling on $\mathrm{HH}$ was also noted as previously suggested in the literature, ${ }^{3,6}$ but our study captures the magnitude of this effect. Whether or not the attending physician cleaned their hands during rounds either positively or negatively influenced $\mathrm{HH}$ compliance of the rest of the physician team $(80 \%$ when compliant vs $20 \%$ when noncompliant).

Our study has several important limitations. The differential Hawthorne effect seen at our center may not reflect other institutions that have numerous $\mathrm{HH}$ auditors or high staff turnover resulting in lower ability to recognize auditors. We cannot exclude the possibility of Hawthorne effect using covert methods that could have affected nurse and physician performance differently, but frequent rotation of the students helped maintain covertness of observations. Finally, due to the nature of the covert student observers, a longer observation time frame could not be sustained.

Our experience using covert $\mathrm{HH}$ auditors suggests that traditional $\mathrm{HH}$ audits not only overstate $\mathrm{HH}$ performance overall, but can lead to inaccurate inferences regarding $\mathrm{HH}$ performance due to relative differences in Hawthorne effect. The answer to the question regarding whether physicians clean their hands appears to be that they do just as often as nurses, but that all healthcare workers have tremendous room for improvement. We suggest that future improvement efforts will rely on more accurate $\mathrm{HH}$ monitoring systems and strong attending physician leadership to set an example for trainees.

Disclosures: This study was jointly funded by the Centre for Quality Improvement and Patient Safety of the University of Toronto in collaboration with Sunnybrook Health Sciences Centre. All authors report no conflicts of interest relevant to this article.

\section{References}

1. World Health Organization. WHO guidelines on hand hygiene in health care. Available at: http://whqlibdoc.who.int/publications/2009/ 9789241597906_eng.pdf. Accessed April 4th, 2015.

2. Pan SC, Tien KL, Hung IC, et al. Compliance of health care workers with hand hygiene practices: independent advantages of overt and covert observers. PLoS One. 2013;8:e53746.

3. Squires JE, Linklater S, Grimshaw JM, et al. Understanding practice: factors that influence physician hand hygiene compliance. Infect Control Hosp Epidemiol. 2014;35:1511-1520.

4. (JCYH) Just Clean Your Hands. Ontario Agency for Health Promotion and Protection. Available at: http://www.publichealthontario.ca/ en/BrowseByTopic/InfectiousDiseases/JustCleanYourHands/Pages/ Just-Clean-Your-Hands.aspx. Accessed August 4, 2015.

5. Allegranzi B, Gayet-Ageron A, Damani N, et al. Global implementation of WHO's multimodal strategy for improvement of hand hygiene: a quasi-experimental study. Lancet Infect Dis. 2013;13:843-851.

6. Schneider J, Moromisato D, Zemetra B, et al. Hand hygiene adherence is influenced by the behavior of role models. Pediatr Crit Care Med. 2009;10:360-363.

7. Srigley JA, Furness CD, Baker GR, Gardam M. Quantification of the Hawthorne effect in hand hygiene compliance monitoring using an electronic monitoring system: a retrospective cohort study. BMJ Qual Saf. 2014;23:974-980.

8. Kohli E, Ptak J, Smith R, et al. Variability in the Hawthorne effect with regard to hand hygiene performance in high- and low-performing inpatient care units. Infect Control Hosp Epidemiol. 2009;30:222225.

9. Borg, MA, Benbachir M, Cookson BD, et al. Self-protection as a driver for hand hygiene among healthcare workers. Infect Control. 2009;30:578-580.

10. Monsalve MN, Pemmaraju SV, Thomas GW et al. Do peer effects improve hand hygiene adherence among healthcare workers? Infect Control Hosp Epidemiol. 2014;35:1277-1285. 